\title{
تعليم القراءة باستخدام معجم أليكترونيك
}

\section{Andi Saefulloh Anwar}

SMK Pariwisata Telkom Bandung

email: andisaefullohanwar@gmail.com

\section{ملخص البحث}

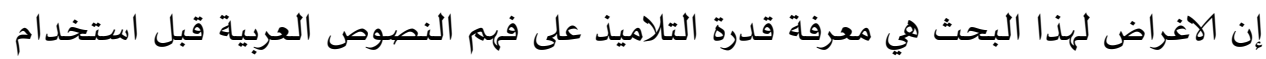

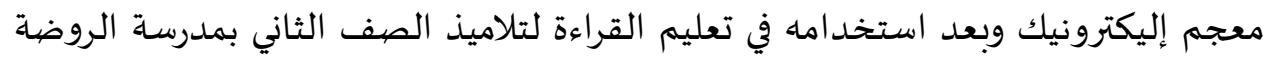

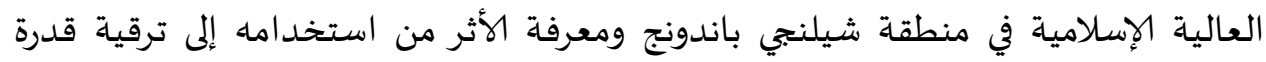

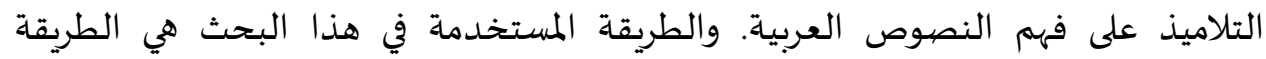

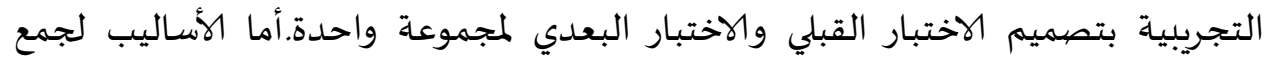

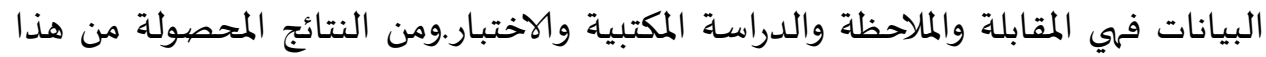

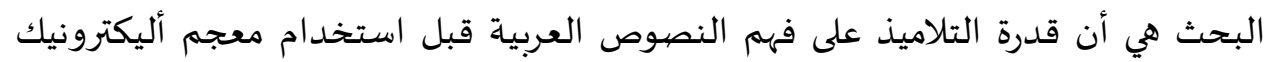

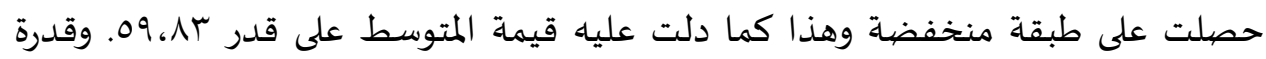

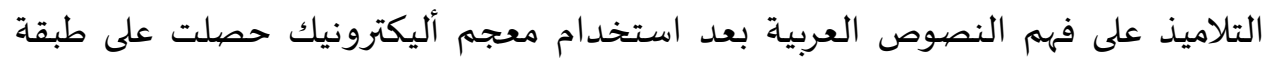

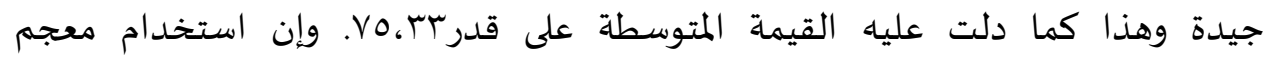

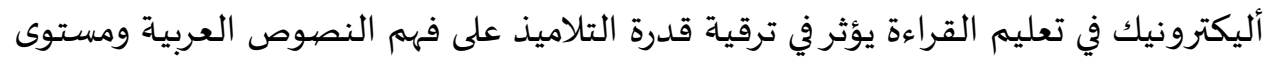

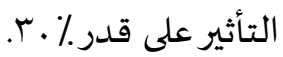

الكلمات الرئيسية: التعليم، القراءة،معجم أليكترونيك.

\begin{abstract}
ABSTRAK
Tujuan dari penelitian ini adalah mengetahui kemampuan siswa kelas XI Madrasah Aliyah Ar-Raudlah Bandung dalam memahami teks bahasa Arab sebelum dan sesudah menggunakan kamus elektronik, serta mengetahui seberapa besar pengaruh kamus elektronik dalam meningkatkan kemampuan siswa dalam memahami teks bahasa Arab. Metode yang digunakan dalam penelitian ini adalah metode eksperimen dengan desain one group pre-test and post-test design. Adapun teknik yang digunakan dalam pengumpulan data yaitu wawancara, observasi, dan tes. Hasil dari penelitian ini diketahui bahwa kemampuan siswa dalam memahami teks bahasa Arab sebelum menggunakan kamus elektronik memperoleh hasil rata-rata 59,83 dan kemampuan siswa dalam memahami teks bahasa Arab setelah menggunakan kamus elektronik memperoleh hasil rata-rata 75,33. Dengan demikian bahwa penggunaan kamus elektronik dalam pembelajaran qiräah memberikan pengaruh terhadap kemampuan siswa dalam memahami teks bahasa Arab dengan persentase $30 \%$.

Kata Kunci: Pembelajaran, Membaca, Kamus, Elektronik.
\end{abstract}




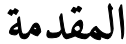

إن اللغة هي واقعية تنشأ وتتطور وفقا لنمو الإنسان الذي يستخدمها. وهي من أهم

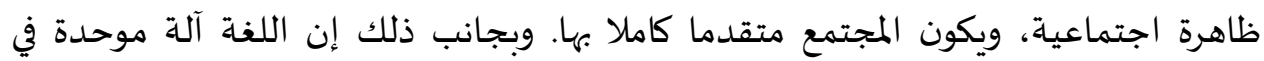

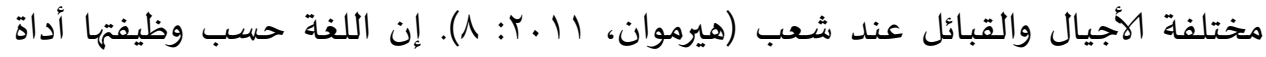

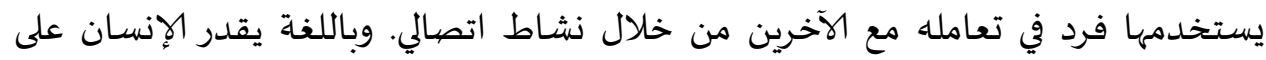

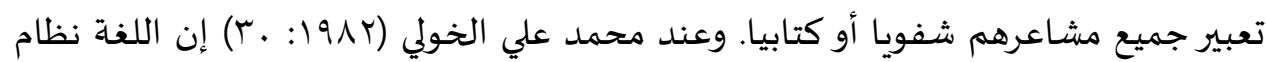

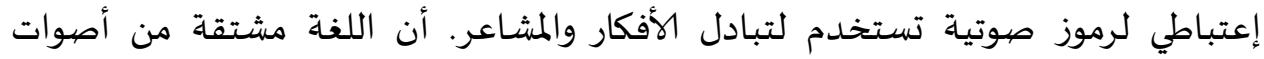

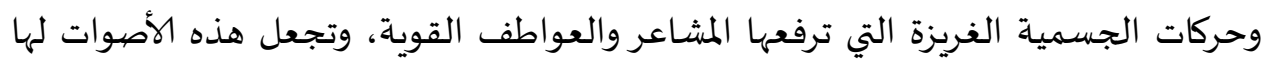

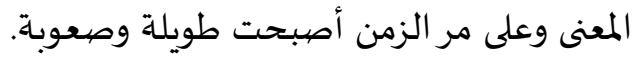

اللغة العربية بجانب استخدامها في نشاط اتصالي دولي، كانت العربية هي لغة الوحي

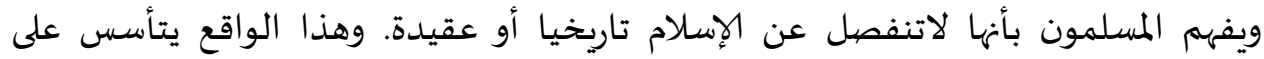

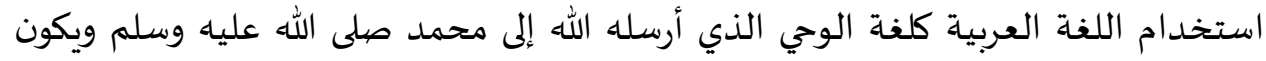

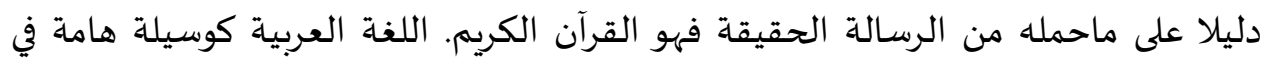

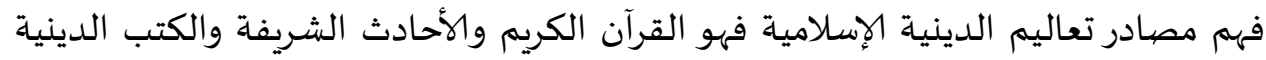

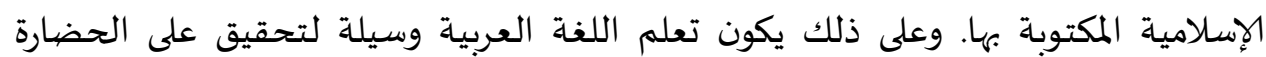

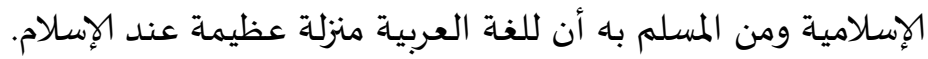

وكانت اللغة العربية اليوم من المواد الدراسية في المدارس الإسلامية وهي معروضانة

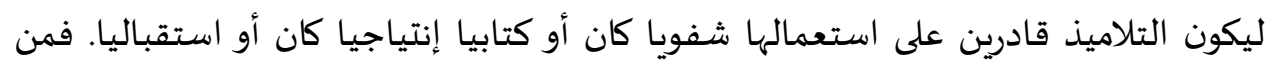

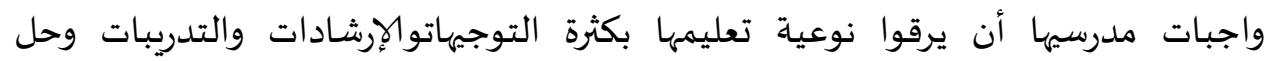
المشكلات التي تواجه التلاميذ في عملية التعليم ليكون إنجازهم في استيعاب المهارات اللغوية نواتية مرتقيا.

ومن المعروف أن تعليم اللغة لاسيما اللغة العربية لاتنفصل إلى تعليم لارتفاع أربع

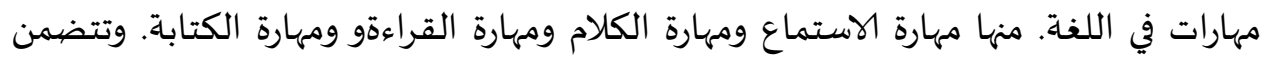

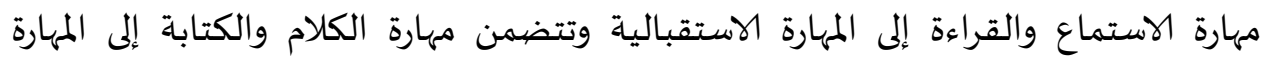

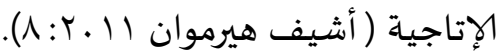


Ta’lim al-'Arabiyyah

ومن جوانب لغوية يلزم التلاميذ على استيعابها فهي مهارة القراءة التي تتضهمن على المهارة الاستقبالية، فتعليم القراءة ليس من جميع أنشطة في نطق النصوص العربية فحسب، بل يستطيع التلاميذ أن يفهموا وحصول على معلومات ممّا قرائههم. وفي هذا السياق يقدر التلاميذ أن يأخدوا ويفهموا المعاني مثلا استطاع تعبير عن المادة المقررة إلى لمان اللغة المفهومة.

وبعد القيام بالملاحظة والمقابلة مع مدرس اللغة العربية في مدرسة الروضية العالية الإسلامية في منطقة شيلنجي باندونج تعرف عدة مشكلات فيها. ومنها عملية التعليم بطريقة المحاضرة ومعه التمرينات ورغبة القراءة المنخفضة وأقل نشاط التلاميذ في الفصل، وهذا يدل على قدرة تعاونهم غير فعاليا وعدم ميل التلاميذ في اعطاء الاستجابة والرأي عمّا يدرسونه في الفصل خاصة في تعليم القراءة. ومعظم التلاميذ لايستطيعون أن يردّدوا عن الأفكار الأساسية ممّا يفهمون من النصوص العربية. وعلى وجه إجمالي أن هذه المشكلات تحدث بسبب عدم قدرة تلاميذ الصف الثاني على استيلاء مهارة القراءة ويصعبون في فهم النصوص العربية بأسباب منها قلة استيعابهم على المفردات العربية. من المقابلة مع مدرس اللغة العربيةيعرف أن قيمة أعلى الذي يحصل على تلاميذ

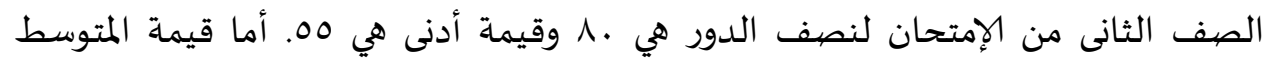
المحصولة هي 70 وهذه لم تصل إلى الحد الأدنى للقيمة المقررة هي . V. من أوضح الأمور أن المفردات من عناصر لغوية يجب الدارس على استيلاء عليها لكي

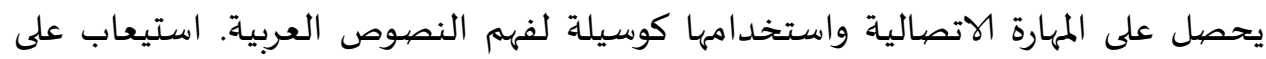
المفردات الكافي مؤثر إلى كيفية اللغة للشخص شفويا كان أو كتابيا. ويكتسبها الفرد من المعاجم والكتب أو من الاستماع.

اليوم قد تطوّر اللغويون عدة الوسائل التعليمية لكي يصل إلى أحسن التعليم. ومؤخرا قد تطوّرت الوسائل التكنولوجية لمساعدة عملية تعليم اللغة العربية، ومنها تطوير الآت الترجمة برمجيات أو على الانترنت.

يهتم الباحث بمعجم أليكترونيك تبعا بتطوير التعليم الإلكتروني الذي يتأثر على

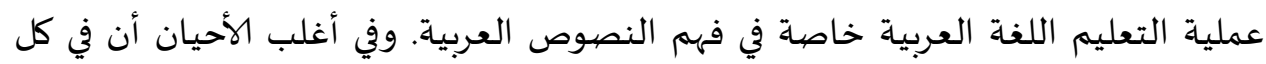
مدارس خاصة في مدرسـة الروضة العالية الإسلامية هناك شيئ لايتحقق في عملية التعليم اللغة العربية فهو استعمال القاموس العبي. 


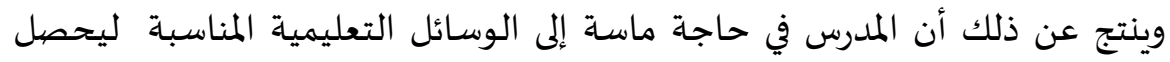

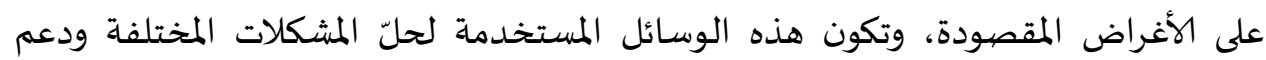

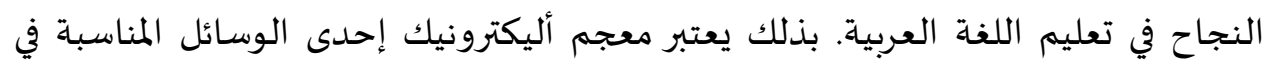
تعليم اللغة العربية خاصة في نشاط التلاميذ في فهم النصوص العربية. ويرجى باستخدام

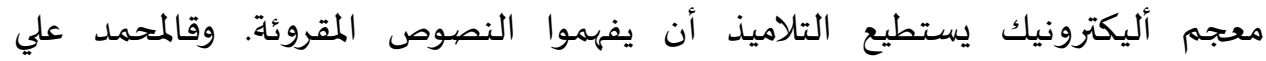

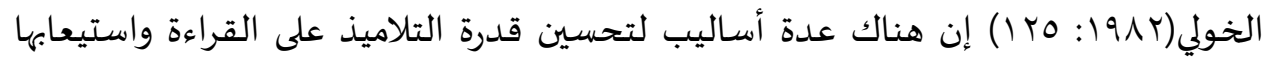

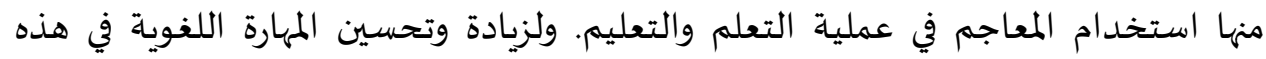

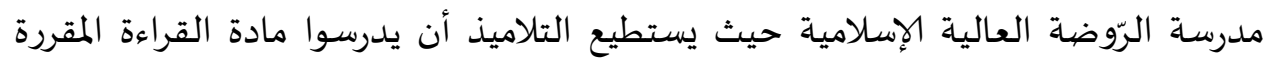

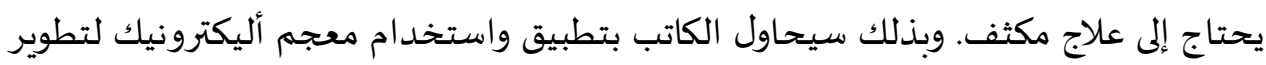

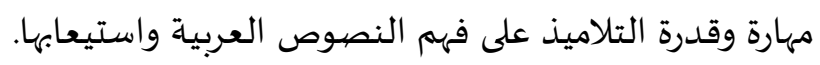
ويعقد هذا البحث في المدرسة الروضة العالية الإسلامية في منطقة شيلنجي باندونج

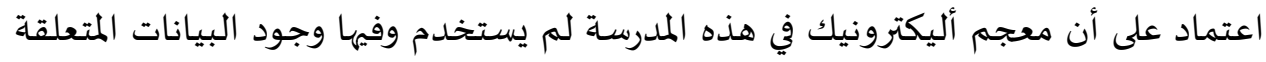

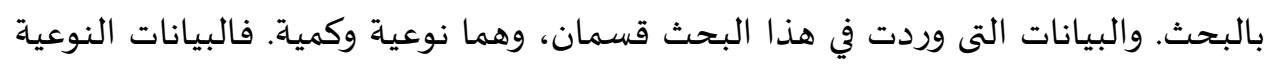

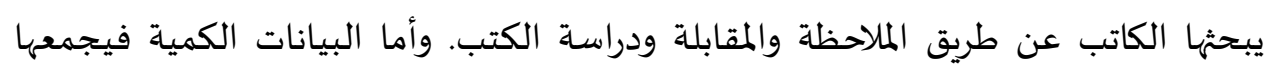
الكاتب عن طريقالاختبارثم التحليل الإحصائي.

أما الطريقة التى تستخدمها الكاتب في هذاالبحث هي الطريقة التجريبية بتصميم

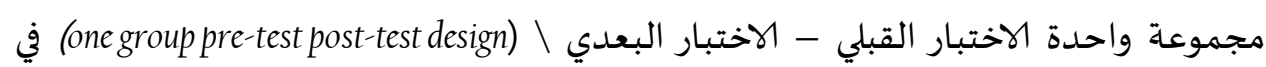

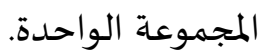

وصفت تصميم البحث على النحو التالي

\begin{tabular}{|c|c|c|}
\hline الاختبار القبلي & العلاج & الاختبار البعدي \\
\hline $\mathrm{O}_{1}$ & $X$ & $\mathrm{O}_{2}$ \\
\hline
\end{tabular}

المعلومات :

الاختبار القبلي قبل العلاج = O O

X العلاج باستخدام معجم أليكترونيك

الاختبار البعدي بعد العلاج 
Ta'lim al-'Arabiyyah

\section{البحث \\ تعليم القراءة}

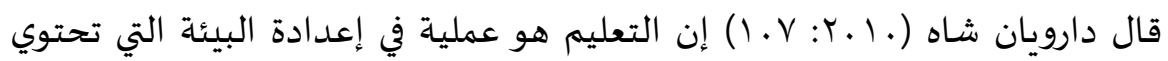
على عدة العناصر التي تؤثر على أهداف التعلم منها العنصر الإنساني والمادي والتسهيلي والتجهيزي والإجرائي. والتعليم أسـاس العملية التعليمية وفيه التفاعل بين المدرس والتلاميذ والمواد الدراسية. وتلك المكونات الأسـاسية تتضمن على البنية التحتية مثل الطريقة والوسيلة وتنظيم المكان الدراسي حتى تجعل عملية التعليم يمكنها حصول على الأغراض المرسومة. والتعليم هو إرشاد نشاط التلاميذ في حصول على المعلومات والمعارف ويدبر إلى تغيير سلوكهم التي تحتوي على الناحية المعرفية والوجدانية والحركية. والتعليم هو تنظيم وتدبير عدة مكونات من الأغراض والتلاميذ والطرق والأحوال والبيئات والتقويم الذي يقوم بها المعلم لكي يقدر التلاميذ على ممارسة أنشطتهم وحصيول على خبرة التعلم. والتعليم مجموعة التي تحتوي على عدة العناصر التي تؤثر على أهداف التعلم منها العنصر الإنساني والمادي

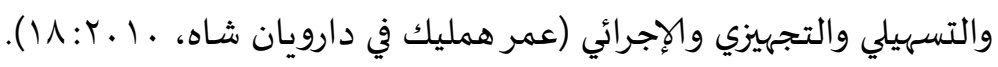

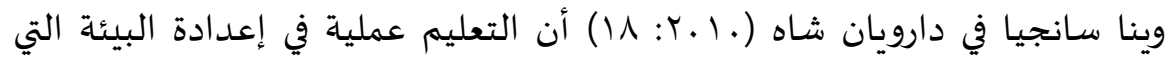
توجاء إلى تغيير سلوك التلاميذ في اتجاه إيجابي وجيد حسب طاقاتهم واختلافهم.

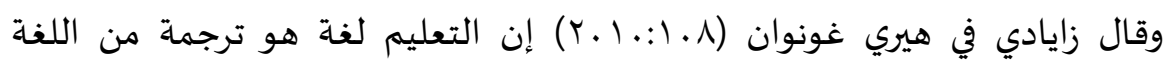
الإنجليزية "instruction "معناها الجهد والمحاولة ليدرس الفرد أو المجتمع من خلال مختلفة المداخل والأساليب والطرق التي توجه إلى حصول على الأهداف المقررة.واصطلاحا كان التعليم هو عملية تنظيم البيئة ليمكن الشخص أن يشارك في سلوكه المعينة وفي الظروف الخاصة أو حصيول على الاستجابة في حالة محددة. والتعلم هو فرعية خاصية من التعليم

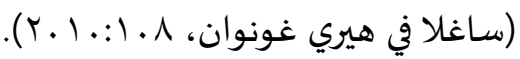

وينتج عن المفاهيم السابقة أن التعليم نظام فهو الذي تضمن وتفاعل فيه عدة المكونات المتفاوت. ويفهم أن التعليم عملية منظمة يمارسها المعلم في التصهيم التعليمي لتحقيق التلاميذ على التعلم إيجابيا الذي يؤكد على توفر مصادر التعلم. وإن التعيلم عملية لا تخلو من الغرض وهو وجود تغير السلوك الجديدة التي تظهر في النواحي المعينة من مثل ئل العلم، والمهارات، والموقف، والعطفة، والابتكار، والاستجابة، والتكيف النفسي، والعادة، 
والتذوق، وغيرها. وكل منها مجموعة في ثلاثة مجالات أساسية تدعي بإنجاز التعلم، وهي مجال معرفي ومجال وجداني ومجال حركي.

\section{خطوات تعليم القراءة}

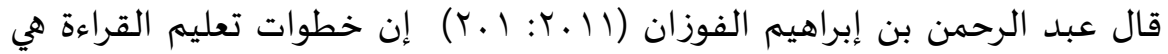

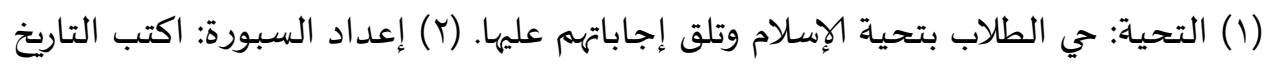

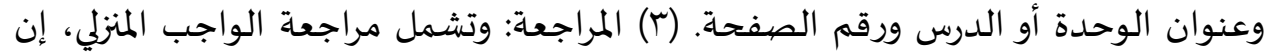
وجد ومراجعة الوحدة السابقة. تتضمن مراجعة العناصر والمهارات اللغوية والمحتوى الثقافئ.

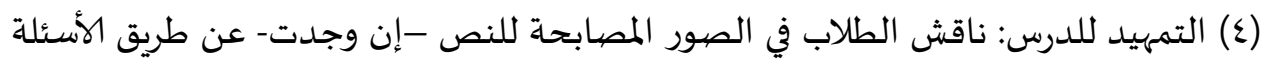

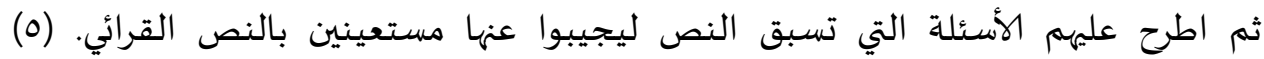

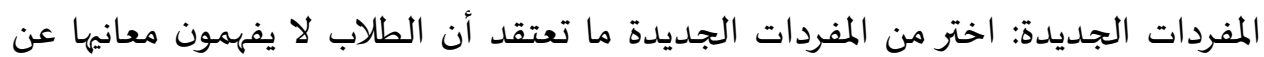

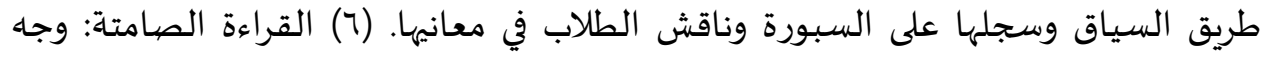
الطلاب لقراءة النص سرا دون صوت للفهه والاستيعاب. (V) تدرببات الاستيعاب والمفردات: بعد القراءة الصامتة، انتقل إلى تدريبات الاستيعاب والمفردات. (م) القراءة الجهرية: اختر

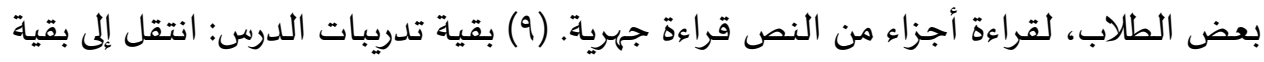

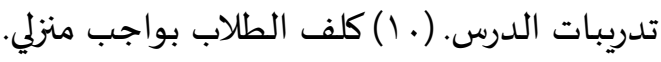

قدرة التلاميذ على فهم النصيوص العربية

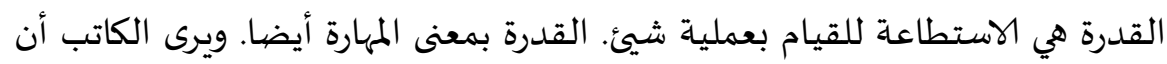

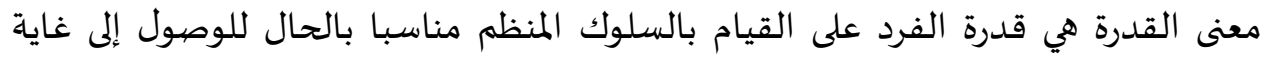

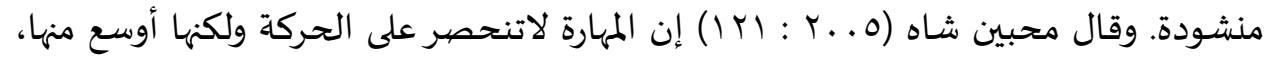

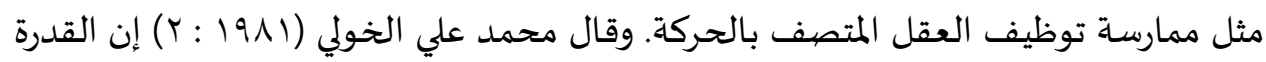

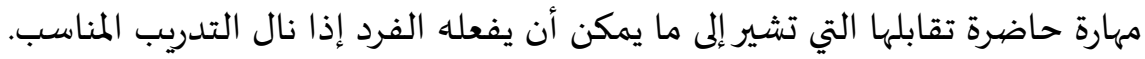
وقال طبراني روسيان (r 199 : 1) إن القدرة هي الاستطاعة والإمكانية في القيام بفعل

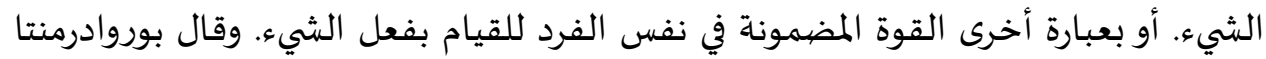

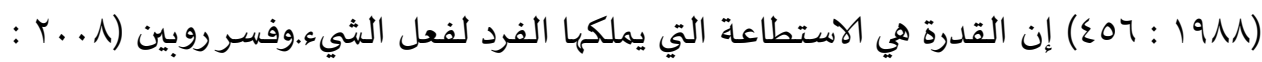

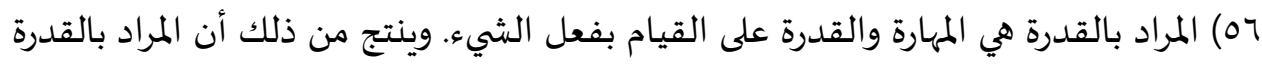
هي الإمكانية أو القوة والاستطاعة للقيام بفعل شيء وفهمادها 
Ta’lim al-'Arabiyyah

قال بنيامين س. بلوم فيما اقتبسه كارتونو(• (.؟: 99) أن القدرة تنقسم إلى ثلاث النواحي فهي الناحية المعرفية والوجدانية والحركية. وإن المجال المعرفي هو تحصيل التعلم الذي يتعلق بالذاكرة والفهه والتطبيق والتحليل والتركيب والتقييم. والمجال الوجداني هو

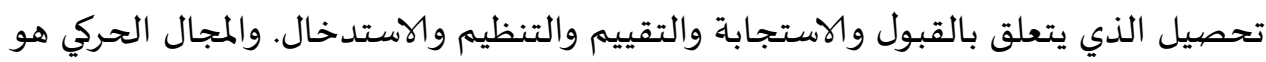
تحصيل التعلم الذي يتعلق بمهارة الحركة المرتكسـة ومهارة الحركة الأسـاسية والقدرة الإدراكية والانسجام والحركات المعقدة والحركة التعبيرية والتفسيرية. وكل من العناصر المذكورة يتعلق بعضها ببعض لأن الفرد الذي يتغير مستواه المعرفي فإن مستواه الوجداني والحركي متغيران على حد معين.

فيما يتعلق بالمجال المعرفي يصنف كينيتح Kenneth في عبد المجيد (O. . Y: ع) مؤشرات على القدرة المعرفية فيما تلي: المعرفة والمذاكرة، الفهه، التطبيق، التحليل، التركيب، والتقييم.

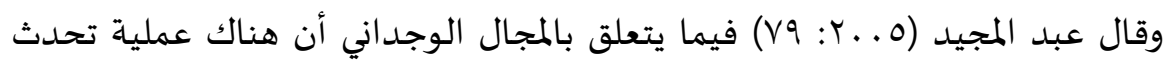
في شخص لعرض السلوك الإيجابي إما السلبي منها: (أ) عملية التكييف (Conditioning)، وهذه أكثر تجربة من علماء النفس مثل نظريةالاستجابةوالتحفيز عند فافلوف والتعزيز عند سكينير وهذه تجربة معروفة باسم تعديل السلوك أو behavior modification. (ب) النمذجـةالبشرية

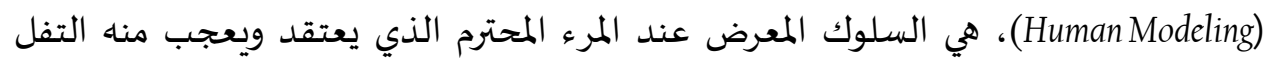
حتى يؤثر على سلوكه وأخلاقه.

\section{مفهوم المعجم الأليكترونيك}

المعجم في قاموس إندونيسيا هو كتاب تجمع كلمات في لغة ما على ذسق منطقي ما وتهذف إلى ربط كل كلمة منها بمعناها وإيضاح علاقتها بمدلولها. قال حنري غونتور (س7 ا: 9 . . أن معجم اسم مفعول من أعْجَم هو كتاب يضهم مفردات لغوية مرتبة ترتيبا معينا

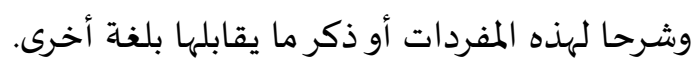

قال علي الخولي في معجم اللغة (ع\&:V91) أن القاموس هو الكتاب الذي يضم مفردات اللغة أو الكلمات المحددة أو يضهم طائفة منها مرتبة ترتيبا خاصيا كل مفردة منها مصحوبة بما يرادفها أو يفسرها ويشرح معناها ويبين أصلها أو اشتقاقاتها، وقد يوضح أصلها ويبين طريقة نطقها ويذكر ما ينظرها ويقابل معناها في لغة أخري. قال بعلبكي (9 (1:. 199) 
المعجم هو كتاب يضم معاني المفردات وكيفية نطقها وهجائها واستعمالها أو أصولها

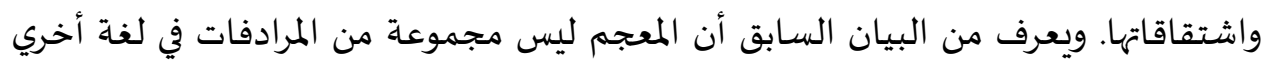
فحسب، بل يجمع الاصطلاحات في مجال العلوم المعينة. المفهوم عند القاسي (19V0:9) المعجم كتاب يشتمل على عدد كبير من مفردات

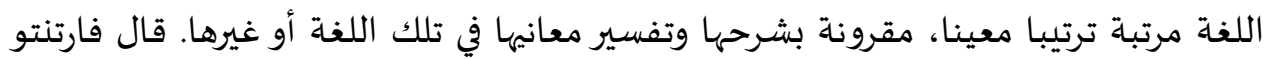
والبر أن القاموس هو كتاب يشتمل على مفردات اللغة ومعناها مرتبة ترتيبا. من المفاهيم السابقة يستنتج الكاتب أن المعجم أو القاموس هو الكتاب الذي يضم

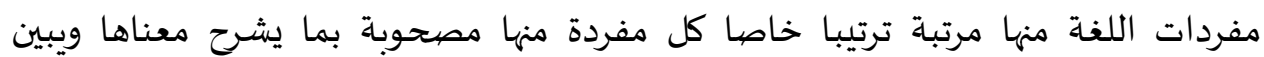
اشتقاقاتها الذي يستخدمه الدارس ليبحث عن المعنى والكلمات الجديدة حسب تعليمها. المعجم الأليكترونيكهو المعجم يتم في شكل أقراص، أو على شكل آلة حاسبة، ويمكن

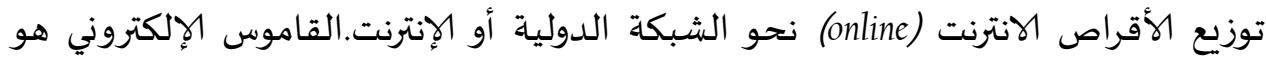
واحد من أحدث التطورات في مجال المعاجم. يقدم هذا القاموس العديد من مزايا التكنولوجيا الحديثة، التي تتألف من أكثر المعلومات من حيث القاموس الطباعي. ويمكن هذا

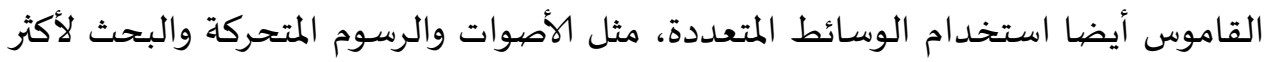

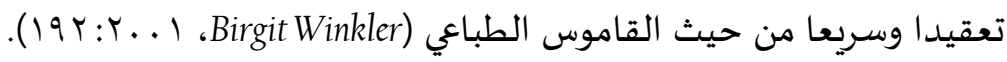

في نفس السياق المعجم الإكتروني هو قاموس البيانات في شكل رقمي، ويمكن

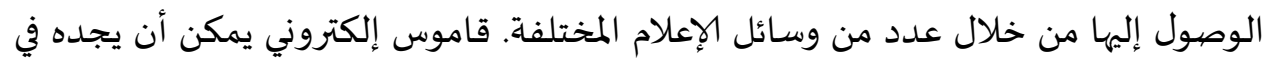

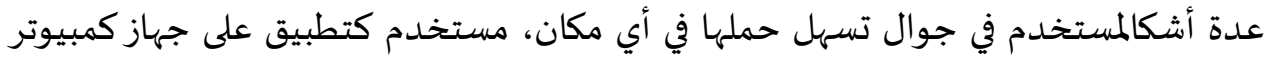

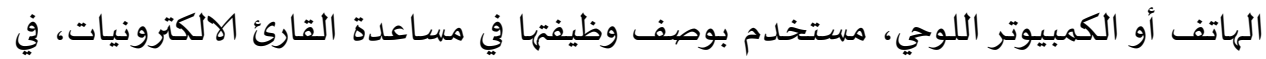
شكل أقراص مدمجة(CD-ROOM)وأقراص الفيديو الرقمية المدمجة (DVD-ROOM) التي

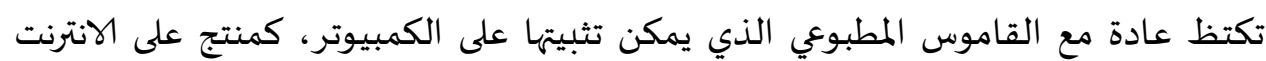

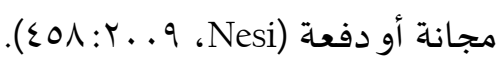

كان قاموس ألكترونيك حسب وظيفته لتسهيل عملية التعلم لاينفصل من المزايا والعيوب. قد ذكر نيسي (1997:OrV) أن هناك المزايا من القاموس الالكتروني : (1) يمكن من المرنايا

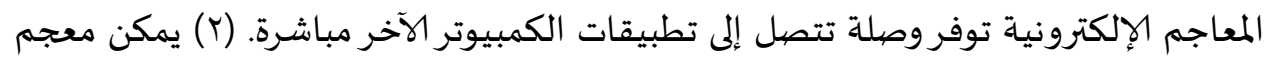

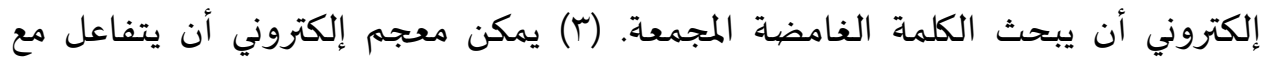

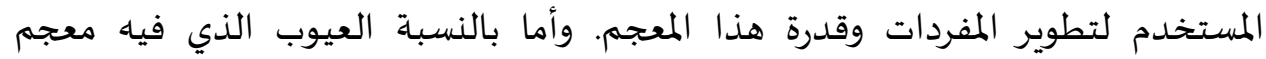


Ta’lim al-'Arabiyyah

ألكترونيك يذكر نيسي في وينكلر (ا . .ب: r 19) على ما يلي: (1) كان قاموس على أقراص مدمجة (CD-ROM)، الذي لم يناسب دائما مع قدرة تخزين أقراص مدمجة (Y) (CD)

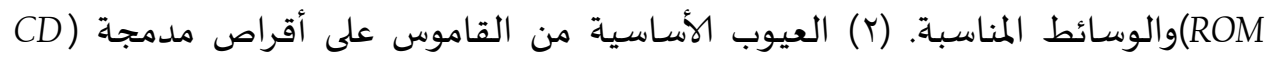

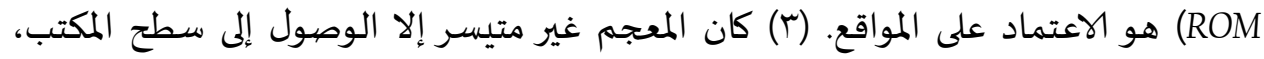
وليس مناسبا بالأغراض الإستقبالية مثل القراءة والاستماع في المحاضرات. وينتج عن ذلك أن المعجم الألكتروني هو القاموس الرقي في شكل البرمجيات الذي يمكن الوصول إلها إنترنتا أو حاليا. للقاموس الكتابي مزايا في عدد من المفردات الكثيرة، ولكن لديها العيوب من حيث بحث المفردات ومعنها الذي يستغرق وقتا طويلا. وبالإضيافة إلى إلى ذلك، أن القاموس الكتابي لا يمكن استخدمه في أي وقت ومكان. يقدر القاموس الألكتروني

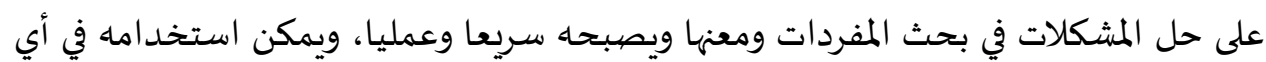
وقت مكان. ومع ذلك، فإن القاموس الالكتروني لدياه العيوب من حيث عدد محدود من الكلمات البيانات. وكذلك القاموس لا يمكن الوصول إليه إلا عن طريق الهواتف ويعتمد على الاتصال بشبكة الإنترنت (القاموس الإلكتروني الانترنت).

\section{واقعية قدرة التلاميذ في فهم النصوص العربية قبل استخدام معجم أليكترونيك} من أوضح الأمور أن المفردات من عناصر لغوية يجب الدارس على استيلاء عليها لكي

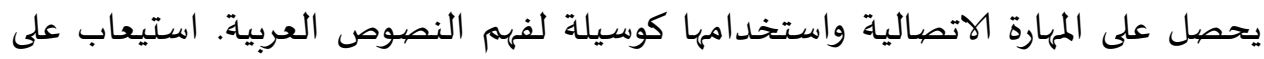
المفردات الكافي مؤثر إلى كيفية اللغة للشخص شفويا كان أو كتابيا. ويكتسبها الفرد من المعاجم والكتب أو من الاستماع.واليوم قد تطوّر اللغويون عدة الوسائل التعليمية لكي يصل فيل فئل إلى أحسن التعليم. ومؤخرا قد تطوّرت الوسائل التكنولوجية لمساعدة عملية تعليم اللغة

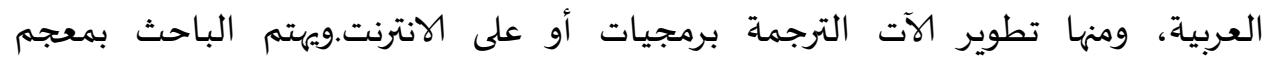
أليكترونيك تبعا بتطوير التعليم الإلكتروني الذي يتأثر على عملية التعليم اللغة العربية خاصة في فهم النصوص العربية. وفي أغلب الأحيان أن في كل مدارس خاصة في مدرسة الروضاة العالية الإسلامية هناك شيئ لايتحقق في عملية التعليم اللغة العربية فهو استعمال القاموس العربي. 
أقيمت مدرسة الروضة العالية الإسلامية في شارع غالومفيت رقم ؟ منطقة شيلنجي

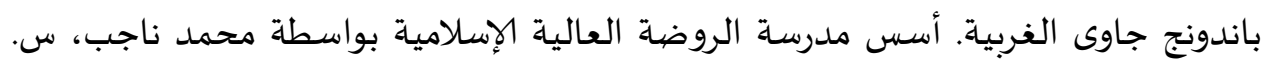

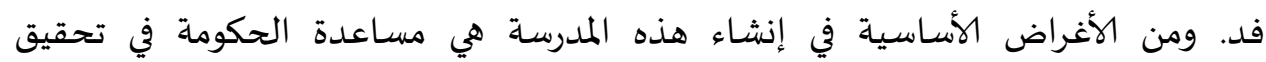

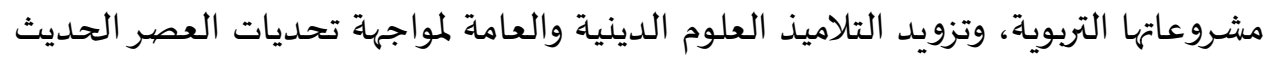

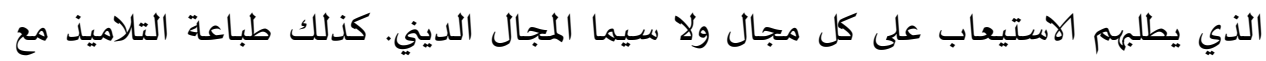

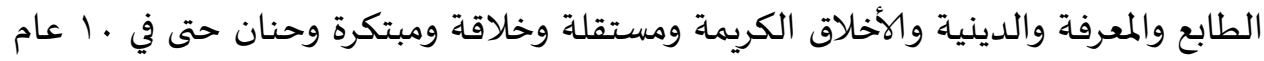

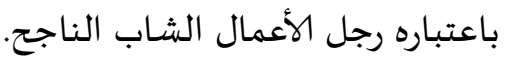

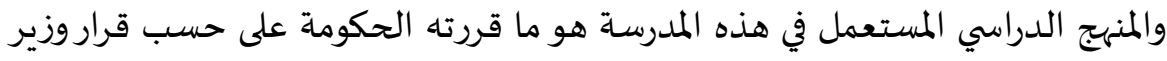

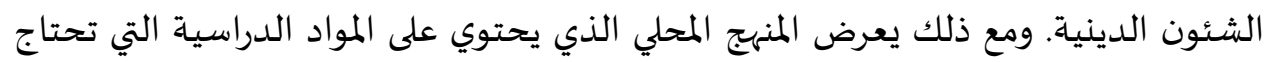

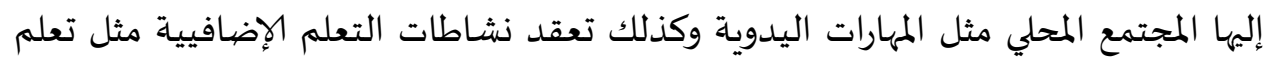

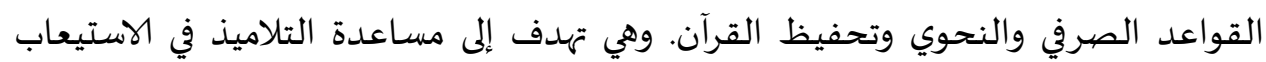

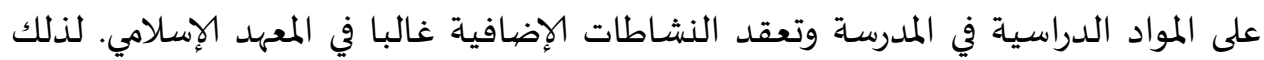

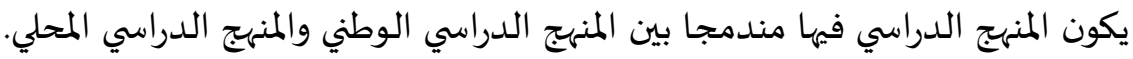
كان عدد المدرسين والموظفين في مدرسة الروضة العالية الإسلامية باندونج للعام

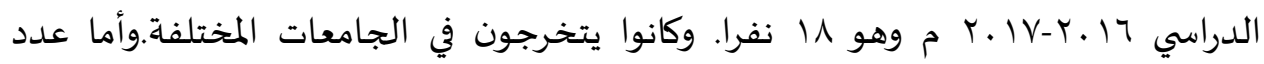

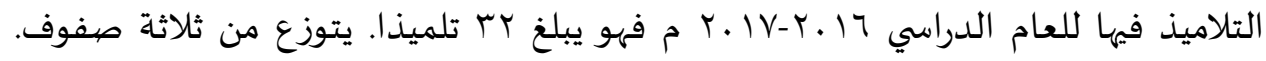

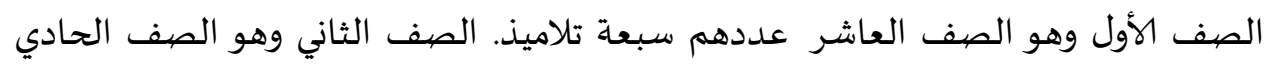

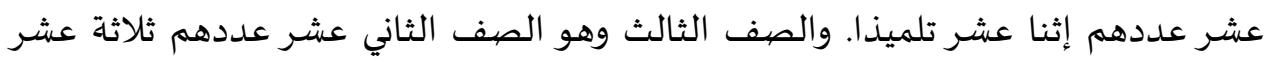
تلميذا. لمعرفة واقعية قدرة التلاميذ على فهم النصوص العربية قبل استخدام معجم المبر

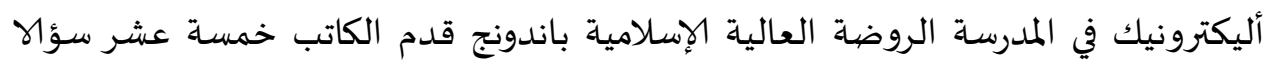

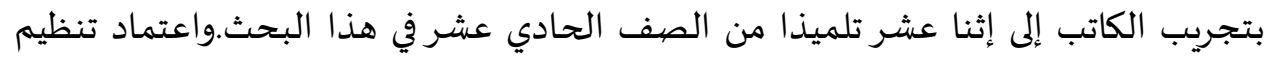

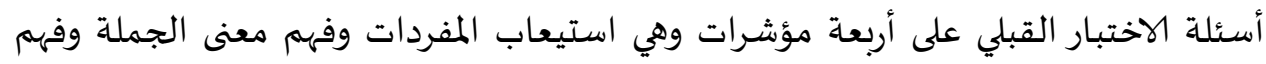

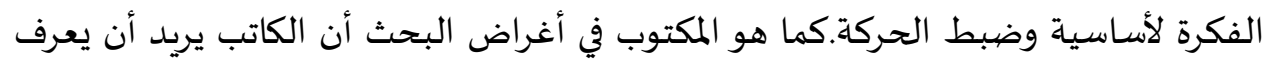

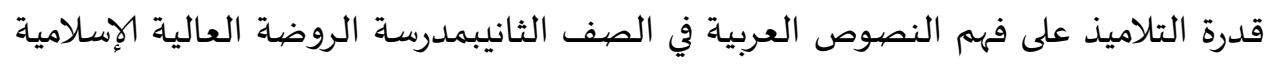

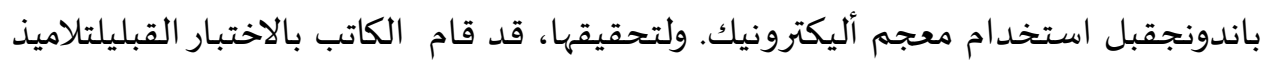

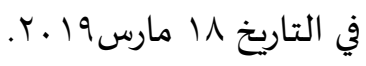


Ta’lim al-'Arabiyyah

وبعد القيام بالاختبار القبلي يجد الكاتب نتائجه لتلاميذ الصف الثانيبمدرسة الروضية العالية الإسلامية باندونجكما الآتي:

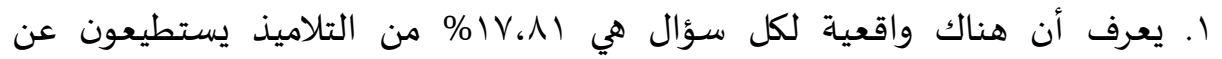

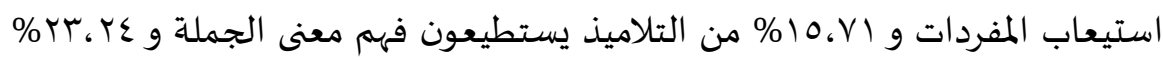
من التلاميذ يستطيعون فهم الفكرة لأساسية وضبط الحركة. r. يعرف أن المجموع من الاختبار القبليVIVا وأما أعلى الدرجة من الاختبار القبلي فهي

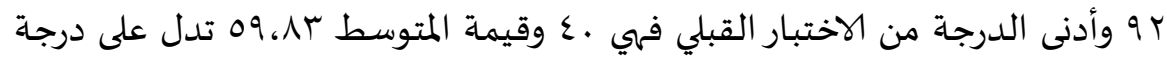
منخفضة لأها تقع بين .0 - 09 في معيار التفسير.

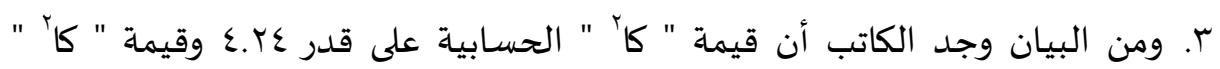

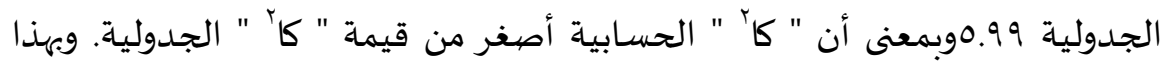

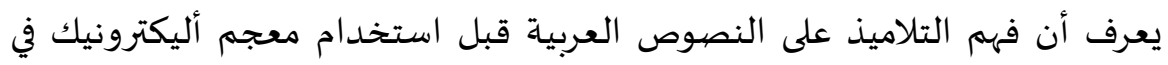

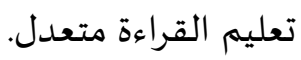

\section{واقعية قدرة التلاميذ في فهم النصوص العربية بعد استخدام معجم أليكترونيك التحان}

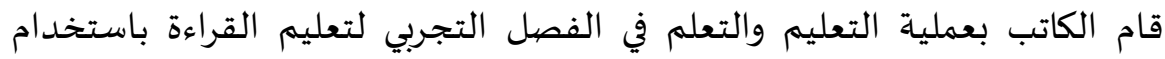
معجم أليكترونيك، ويكون هذا الفصل من إثنا عشر تلميذا. ويشترك التلاميذ اشتراكا فيها

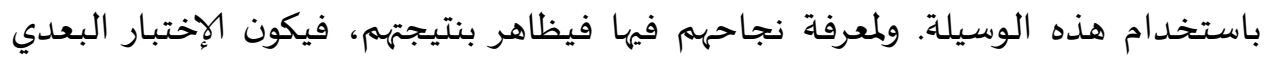

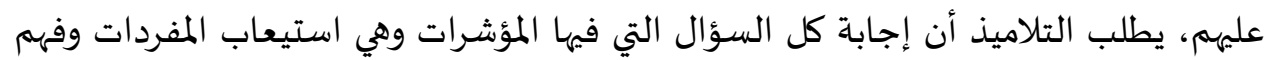
معنى الجملة وفهم الفكرة لأساسية وضبط الجابه كل الحركة.

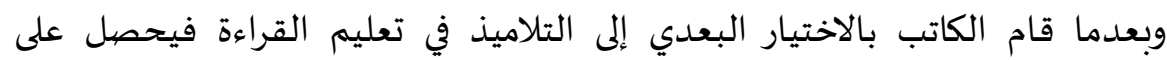

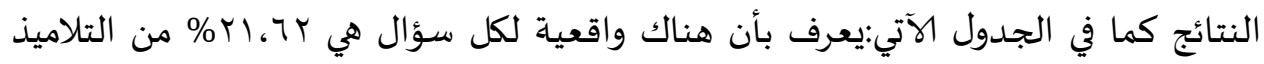

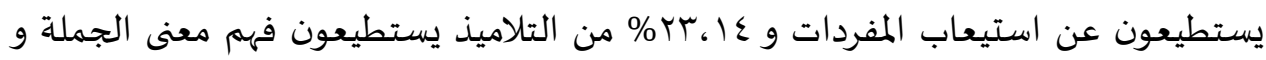

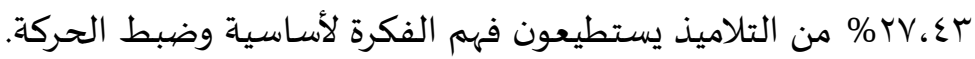


يعرف أن أعلى درجة النتيجة من الاختبار البعدي هي ؟9 وأدنى درجةالنتيجة من

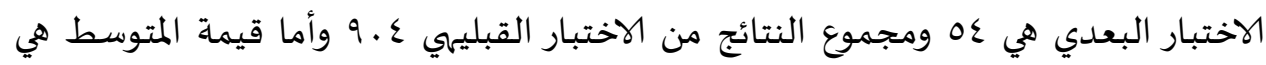

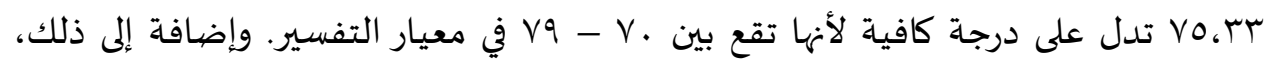

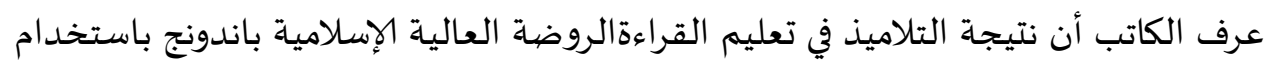

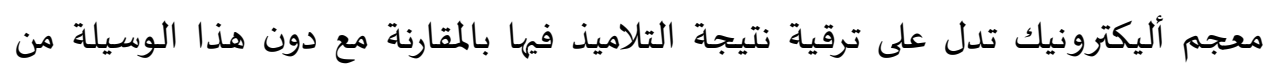

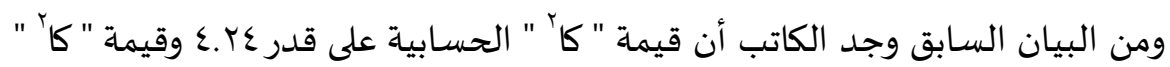

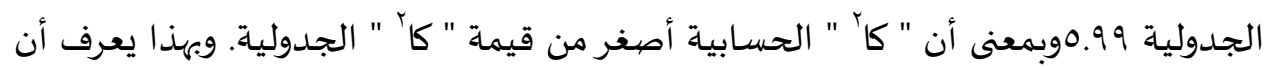

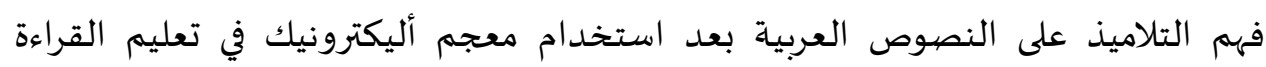

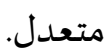

واقعية أثر استخدام معجم أليكترونيك في تعليم القراءة في قدرة التلاميذ على فهم النصوص العربية ولمعرفة حقيقة أثر استخدام معجم أليكترونيك في تعليم القراءة في قدرة على فهم

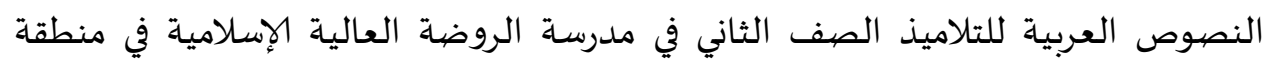

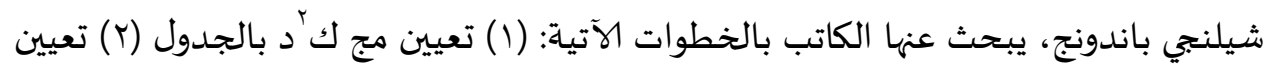

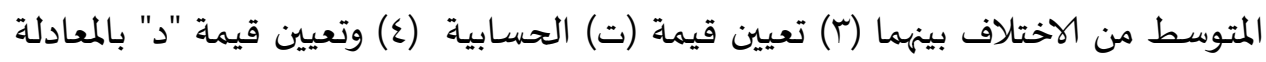
الآتية:

د =نتيجة الاختبار النهائي - نتيجة الاختبار لإبتدائي

أقصى الدرجة الممكنة - نتيجة الاختبار لإبتدائي

ومن البيان السابق وجد الكاتب أن قيمة "ت" الحسابية على قدر 1..0 وقيمة "ت

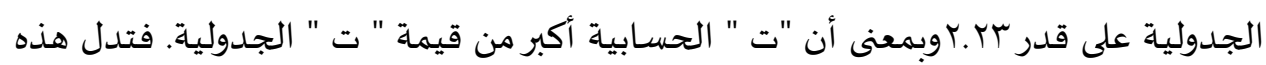

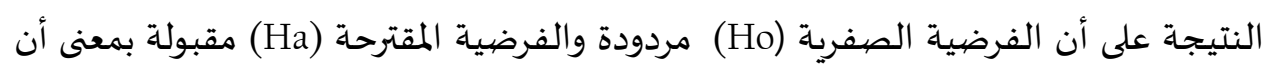

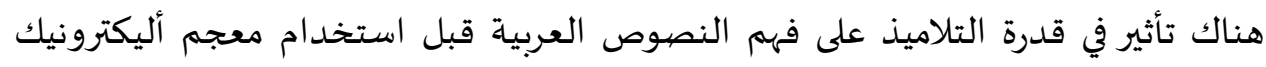
وبعلهه. 
Ta'lim al-'Arabiyyah

يعرف أن أعلى الدرجة من قيمة "د" VY.. . وأدنى الدرجة من قيمة "د" ه. .- . وقيمة

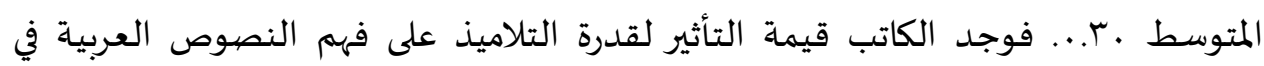

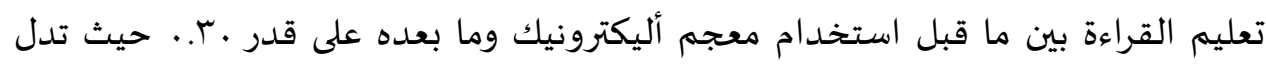

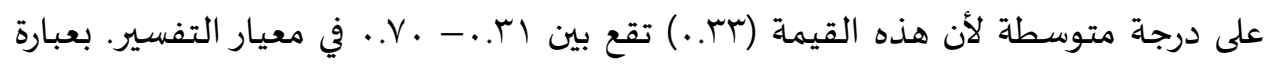

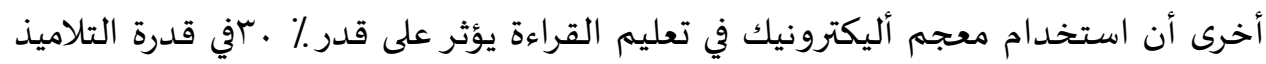
على فهم النصوص العربية و. . أحن العوامل الأخرى.

\section{النتيجة}

بعد القيام بالبحث في مدرسة الروضة العالية الإسلامية شيلجي باندونج وتحليل بياناته يقدم الكاتب النتائج الآتية: (1) إن قدرة التلاميذ على فهم النصيوص العروضة العربية في تعليم

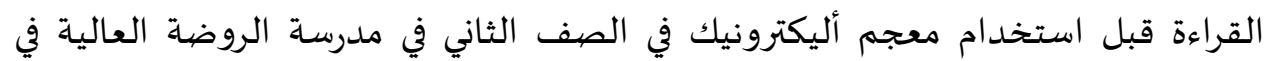

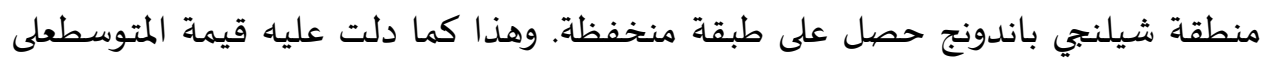

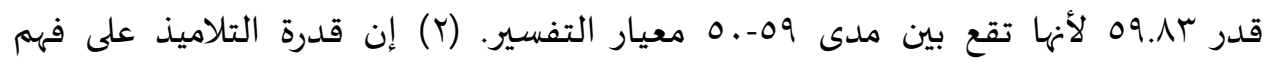

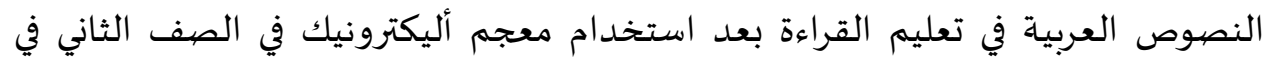

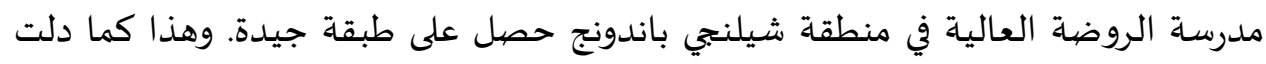

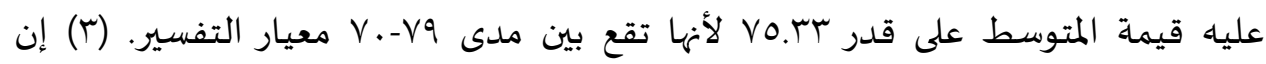

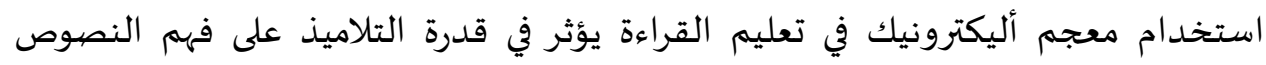

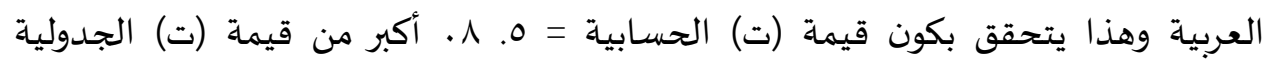

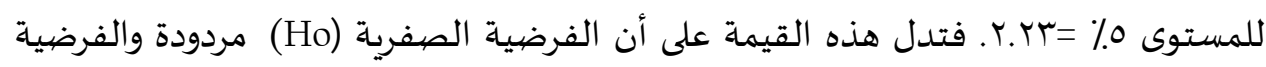

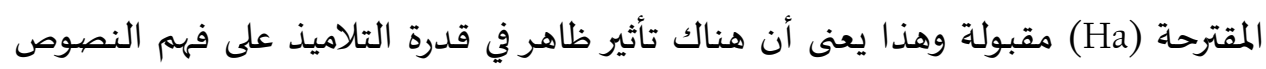

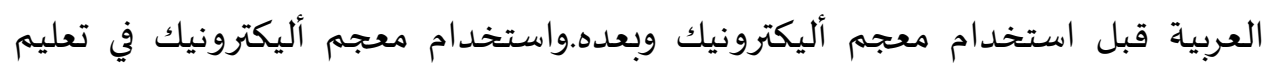

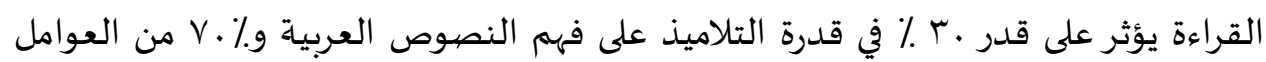
الأخرى . 
Al-Fauzan, Abdul Rahman Ibrahim. 2011. Iḍ̂äat li Mu'allimi al-Lughah al-Arabiyyah Lighairi al-Nathqüna Bihā. Riyad.

Al-Khuli, Muhammad Ali. 1981. Asälib Tadris al-Lughah al-'Arabiyyah. Riyadh: alMamlakah al-'Arabiyyah. . 1991. A Dictionary of Theoritical Linguistics, English-Arabic. Libanon: Librarie du Liban.

Al-Qasimi, Ali. 1975. 'Ilm al-Lughahwa Shinäah al-Mu'jam. Riyadh: Jāmi'ah alMamlakah al-'Arabiyyah as-Su'ūdiyyah.

Arikunto, Suharsimi. 2010. Prosedur Penelitian Suatu Pendekatan Praktik. Jakarta: RinekaCipta.

Birgit, Winkler. 2001. English learners' dictionaries on CD-ROM as reference and language learning tools, Journal Cambridge.

Fakhrurrozi, Aziz dan Erta Mahyudin. 2012. Metodologi Pembelajaran Bahasa Arab.Jakarta: Dirjen Pendidikan Islam Kementerian Agama. 2012. Teknik Pembelajaran Bahasa Arab. Jakarta: Pustaka Cendekia Utama.

Gunawan, Heri. 2010. Kurikulum dan Pembelajaran Pendidikan Islam. Bandung: Alfabeta. . 2011. Dasar-dasar Metode Research. Bandung: Azfie Media Utama.

Hermawan, Acep. 2011. Metodologi Pembelajaran Bahasa Arab. Bandung: PT Remaja Rosdakarya.

Mahmud. 2011. Metode Penelitian Pendidikan. Bandung: CV Pustaka Setia.

Nesi, H. 1996. For future reference?A review of current electronic learners'dictionaries. System, 24 (4): 537-57.

Nuha, Ulin. 2012. Metodologi Super EfektifPembelajaran Bahasa Arab.Yogyakarta: Diva Press.

Syah, Darwyan. 2010. Kurikulum dan Pembelajaran. Bandung: HajaMandiri.

Tarigan, Henri Guntur. 2009. Pengajaran Kedwibahasaan. Bandung: Angkasa. 